\title{
IDENTIFIKASI SIGNIFICANT VALUE PADA LANSKAP BUDAYA SUKU MATABESI SEBAGAI UPAYA PENGEMBANGAN PARIWISATA DAN EKONOMI KREATIF KABUPATEN BELU
}

\author{
Nuraini ${ }^{1}$, Irawan Setyabudi ${ }^{1}$, Novica Christiani Pareira ${ }^{2}$ \\ ${ }^{1)}$ Staf Pengajar Program Studi Arsitektur Lanskap Fakultas Pertanian Universitas Tribhuwana Tunggadewi \\ ${ }^{2)}$ Mahasiswa Program Studi Arsitektur Lanskap Fakultas Pertanian Universitas Tribhuwana Tunggadewi
}

\begin{abstract}
ABCTRACT
The Matabesi tribe is the oldest tribe in Belu Regency. The Matabesi Tribe community lives and develops into a traditional village. Matabesi society still use nature and the environment to fulfill their daily lives. The Matabesi Tribe area has a lot of tourism potential that bus is developed into a cultural tourism area. The purpose of this study was to identify the Significant Value possessed by the Matabesi Tribe. This research uses descriptive method, observation and indepth interview with key person to determine the significant value. Research result the cultural landscape area of Matabesi Tribe has 5 significant values namely history, science, culture, religion and education. Based on Tourism Law No. 10 of 2009 concerning tourist destinations, the Matabesi Tribe can be developed which can support the creative economy of the Matabesi Tribe through the development of facilities, developing tourist attraction and developing accessibility derived from the local wisdom of the Matabesi Tribe.
\end{abstract}

Keyword: Creative Economy, Culture, Cultural Landscape, Local Wisdom, Tourism

\begin{abstract}
ABSTRAK
Suku Matabesi merupakan suku tertua di Kabupaten Belu. Masyarakat Suku Matabesi tinggal dan berkembang menjadi satu perkampungan adat. Masyarakat Suku matabesi masih memanfaatkan alam dan lingkungan untuk memenuhi kehidupan sehari-harinya. Kawasan Suku Matabesi memiliki banyak potensi wisata yang dapat dikembangkan menjadi kawasan wisata budaya. Tujuan penelitian ini adalah untuk mengidentifikasi Significant Value yang dimiliki oleh Suku Matabesi. Penelitian ini menggunakan metode deskriptif, observasi dan wawancara mendalam dengan key person untuk mengetahui significant value. Hasil penelitian kawasan lanskap budaya Suku Matabesi memiliki 5 significant value yaitu sejarah, ilmu pengetahuan, budaya, agama dan pendidikan. Berdasarkan Undang-Undang Kepariwisataan no 10 tahun 2009 tentang daerah tujuan wisata kawasan budaya Suku Matabesi dapat dikembangkan kegiatan wisata yang dapat mendukung ekonomi kreatif masyarakat Suku Matabesi melalui pengembangan fasilitas, pengembangan daya yarik wisata serta pengembangan aksesibilitas yang bersumber dari local wisdom masyarakat Suku Mata Besi.
\end{abstract}

Keyword: Budaya, Ekonomi Kreatif, Kearifan Local, Lanskap Budaya, Pariwisata 
PENDAHULUAN

Suku Matabesi secara administratif terletak pada Kelurahan Umanen Fatuketi, Kecamatan Atambua, Kabupaten Belu, Nusa Tenggara Timur. Kawasan Suku Matabesi memiliki batas Utara berbatasan dengan Kelurahan Manumutin, batas Selatan berbatasan dengan Kelurahan Lidak, batas Barat berbatasan dengan Desa Fatuketi dan batas Timur berbatasan dengan Kelurahan Tulamalae.

Suku Matabesi merupakan suku tertua di Kabupaten Belu. Suku Matabesi berkembang melalui pemukiman yang mana seluruh masyarakat tinggal pada kawasan tersebut adalah masyarakat Suku Matabesi sehingga kawasan tersebut menjadi perkampungan adat. Masyarakat adat Suku Matabesi masih memanfaatkan alam dan lingkungan dalam menjalankan kehidupan sehari-harinya.

Lanskap budaya yang terkandung dalam kawasan adat suku Matabesi memiliki banyak potensi untuk dikembangkan. Menurut Platcher dan Rossler (1995) lanskap budaya tercipta dikarenakan adanya hubungan antara manusia, sistem sosialnya, dan cara mereka untuk mengatur ruang, hubungan tersebut dimulai dengan usaha manusia untuk menaklukan alam dengan pola pikir dan kemampuannya sehingga tercipta suatu tatanan tersendiri pada suatu lanskap.
Dengan memperhatikan beberapa potensi yang ada, lanskap Suku Matabesi dapat dikembangkan menjadi kawasan wisata budaya. Oleh karena itu, penelitian ini dilakukan untuk mengidentifikasi Significant Value yang dimiliki oleh lanskap kawasan Suku Matabesi yang akan menjadi potensi awal pengembangan kawasan menjadi kawasan pariwisata dan ekonomi kreatif di Kabupaten Belu Nusa Tenggara Timur.

\section{METODE PENELITIAN}

Penelitian ini dilakukan pada kawasan budaya suku Matabesi Kabupaten Belu, Nusa Tenggara Timur. Data yang disajikan dalam bentuk deskriptif.

Metode yang digunakan dalam penelitian ini adalah metode deskriptif, observasi dan wawancara mendalam dengan key person untuk mengetahui significant value.

Penilaian Significant Value dilakukan mengacu pada Supriadi (2010), Nursyirwan et al (2015), dan Nuraini et al (2015) serta dimodifikasi dari UU No. 11 Tahun 2010 tentang Heritage. Terdapat 5 Significant Value yang dikaji yaitu Sejarah, ilmu pengetahuan, budaya, pendidikan dan agama.

\section{HASIL DAN PEMBAHASAN}

\section{Sejarah}

Pada dasarnya, masyarakat yang tinggal di Kabupaten Belu merupakan masyarakat 
pendatang yang berasal dari Sina Mutin Malaka. Masyarakat dari Malaka tersebut tinggal dan menyebar sehingga membuat kelompok masing-masing diwilayah Nusa Tenggara Timur.

Suku Matabesi merupakan salah suku yang berkembang di Kabupaten Belu terletak di Kelurahan Umanen Fatuketi, Kecamatan Atambua Barat Kabupaten Belu Provinsi Nusa Tenggara Timur.

Masyarakat suku Matabesi dikenal dengan sebutan ema fatuk oan ema ai oan (manusia penghuni batu dan kayu). Karakter orang pada suku Matabesi adalah berpostur kuat, kekar dan bertubuh pendek.

Masyarakat suku Matabesi menjadi salah satu suku tertua di Kabupaten Belu yang masih tergantung pada alam dan lingkungannya.

Nama suku Matabesi berasal dari Bahasa asli suku tersebut yaitu Beulunan Lao Dinan Rai, Nabelan Rai Beda Rai, yang memiliki arti tiga bersaudara yang berjalan dari Pulau Bali ke Pulau Timor yang tinggalnya berpencar dan berkembang.

Berkembangnya masyarakat suku Matabesi tersebut seiring dengan berkembangnya pemukiman masyarakatnya.

Pola pemukiman yang terdapat pada kawasan ini menjadi salah satu contoh pemukiman yang berkembang di Kabupaten Belu sampai dengan saat ini.

Pemukiman masyarakat suku Matabesi memiliki tipe cluster, dengan "uma Bot" sebagai sentral atau pusat perkampungan. Perletakan tempat rumah pada cluster ini dianggap sakral, sementara tempat pemukiman kepala Suku Matabesi terletak di depan kampung, yakni pada daerah yang lebih tinggi. Selain itu, di depan tiap rumah kepala adat diletakkan batu persembahan (aitos), sebagai tempat berlangsungnya upacara adat.

Tatanan pemukiman pada perkampungan Suku Matabesi, mewajibkan tiap rumah yang didirikan harus berorientasi ke arah Timur atau menghadap Lakaan yaitu gunung tertinggi di Kabupaten Belu.

Kampung Suku Matabesi terletak diatas puncak bukit dengan topografi yang berundak - undak. Kampung ini dikelilingi oleh kebun (To'os) sebagai pembatas desa yang dimanfaatkan oleh penduduk sebagai lahan pencaharian. Di samping itu, yang juga menjadi pembatas fisik kampung adalah kondisi topografi yang curam.

Sampai dengan saat ini, masyarakat suku matabesi tinggal dirumah adat warisan nenek moyang (Gambar 1) tanpa merenovasi guna untuk mempertahankan adat dan warisan leluhur Suku Matabesi.

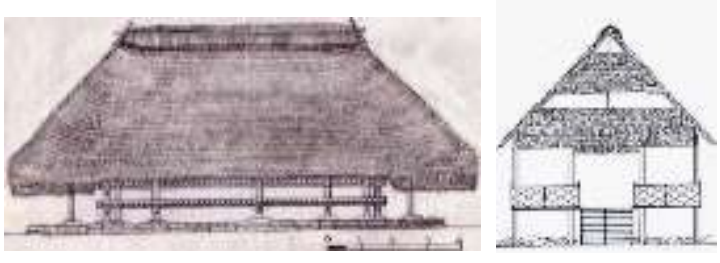

Gambar 1. Rumah Adat Suku Matabesi

\section{Ilmu Pengetahuan}

Sistem ilmu pengetahuan yang terjalin di lingkungan masyarakat Suku Matabesi 
terletak pada corak kain tenun. Kain tenun atau yang disebut dengan tais oleh masyarakat suku Matabesi dibuatkan motif dengan teknik futus, fafoit dan sui.

Kain tenun laki-laki dan kain tenun wanita memiliki motif dan corak yang berbeda. Kain tenun laki-laki disebut dengan Tais mane memiliki motif garis vertical atau tegak lurus yang mana motif tersebut melambangkan tanggung jawab seorang laki-laki terhadap kelangsungan hidup keluarga dengan sang pencipta, sedangkan kain tenun wanita atau disebut dengan tais feto memiliki motif kecilkecil dan melingkar, motif ini melambangkan seorang wanita yang selalu berada dalam kuasa dan perlindungan suami.

Kedua perbedaan motif ini masih dilestarikan sampai dengan saat ini, dengan harapan masing-masing peran dalam rumah tangga pada masyarakat Suku Matabesi dapat dilaksanakan dengan baik. Adapun motif kain tersebut dapat dilihat pada gambar 2 berikut ini.

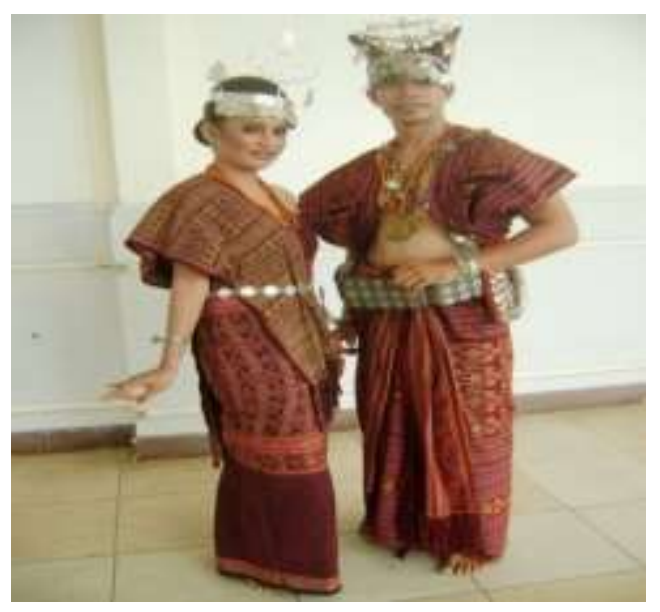

Gambar 2. Motif Tais Feto dan Tais Mane

\section{Budaya}

Masyarakat suku Matabesi memiliki tradisi adat yang masih dikembangkan sampai dengan saat ini, adapun tradisi tersebut diantaranya adalah upacara perkawinan yang di sebut dengan kawen, upacara kelahiran yang disebut dengan ema moris, dan upacara kematian yang disebut dengan ema mate.

Masyarakat suku Matabesi menganut system perkawinan (kawen) patrilineal, pada suku Matabesi seorang wanita memiliki kedudukan yang sangat tinggi derajatnya. Sesudah kawin seorang wanita dianggap sebagai uma nain atau wanita tuan rumah.

Terdapat tiga jenis perkawinan yang di haramkan terjadi pada masyarakat suku Matabesi yaitu perkawinan antara saudara sekandung, jika terjadi maka ungkapannya: asu matan at (anjing yang buta matanya), Oan susun yaitu perkawinan ayah dengan anak kandungnya, jika terjadi pelanggaran tersebut, maka diistilahkan asu na nikar oan, manu nemu nikar tolun (anjing memakan kembali anaknya, ayam meminum kembali telurnya), Oan no inan, yaitu perkawinan antara anak laki- laki dengan ibunya, jika terjadi pelanggaran, maka perbuatannya dikatan asu sae tetu, asu nador kaok (anjing menaiki loteng, mengotori sarang).

Apabila terjadi perkawinan incest maka akan dihukum dengan hukuman yang keras yaitu pria dan wanita dipaksa untuk mengisap usus babi (fahi ten), serta dikucilkan dari suku (lelen sai). 


\section{Pendidikan}

Masyarakat Suku Matabesi merupakan suku yang sangat tergantung dengan alam. Sehingga segala aktivitas masyarakatnya sangat berkaitan erat dengan keadaan alam. Salah satu unsur pendidikan yang sangat relevan pada suku Matabesi ini adalah hubungan masyarakat Suku Matabesi dan hutan. Keduanya menjadi satu kesatuan yang tidak bisa dipisahkan,

Mayoritas mata pencaharian masyarakat suku Matabesi adalah pertanian. Masyarakat memanfaatkan hutan mereka untuk mengembangkan pertanian. Berdasarkan hasil pengamatan, terdapat beberapa aktivitas ritual yang dilakukan oleh masyarakat yang berhubungan dengan siklus pertanian.

Aktivitas ritual dalam siklus pertanian adalah upacara Lakumatebian yaitu ritual adat dengan memotong hewan serta berdoa bersama agar lading yang mereka tanam dapat menghasilkan hasil yang maksimal. Hamis batar merupakan salah satu kegiatan dilakukan oleh masyarakat yang di pimpin oleh ketua adat untuk menyambut musim panen. Batar fohon yaitu ritual adat berupa pencabutan pohon atau tanaman di ladang setelah panen hal ini dilakukan agar lahan mereka kembali menjadi bersih sehingga dapat dimanfaatkan kembali.

Ritual-ritual yang dilakukan dalam siklus pertanian tersebut pada dasarnya adalah sebagai wujud bentuk rasa terima kasih terhadap Tuhan Yang Maha Esa terhadap hasil yang didapatkan. Adapun salah satu bentuk ritual adat dalam siklus pertanian adalah sebagai berikut (Gambar 3)

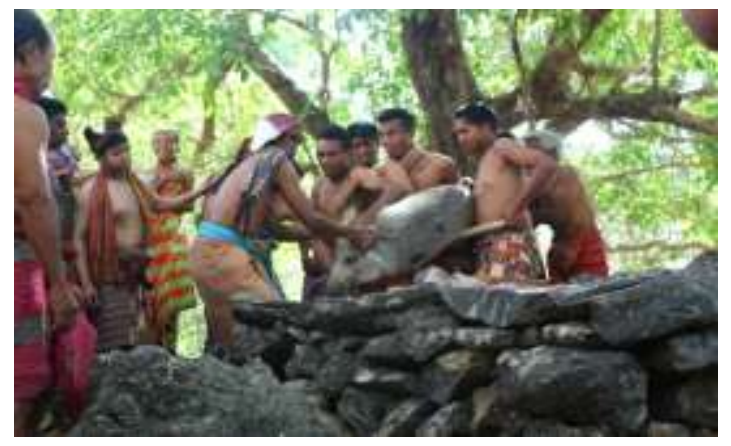

Gambar 3. Salah Satu Ritual dalam Siklus Pertanian yaitu Lakumatebian

\section{Agama}

Masyarakat Suku Matabesi tinggal dan mendiami puncak bukit. Hal ini dikarenakan masyarakat Suku Matabesi secara spiritual masih menganggap bahwa puncak bukit merupakan salah satu symbol yang menghubungkan kehidupan permukiman mereka sebagai mikrokosmos dengan alam sebagai tempat yang kuasa. Alam dijadikan sebagai symbol kepemilikan sebagai makrokosmos.

Masyarakat Suku Matabesi memiliki tempat dan aktivitas pendukung ritual keagamaan dan kepercayaan, diantaranya adalah:

\section{Aitos}

Aitos merupakan salah satu tempat yang memiliki fungsi untuk meletakkan persembahan dalam ukuran besar seperti kerbau, babi maupun ayam,

\section{Sadan Sri Fo’o}

Sadan Sri Fo'o Lakaan merupakan tempat untuk menaruh persembahan kemenangan 
Nuraini dan Irawan Setyabudi, Jurnal OPTIMA Volume II Nomor 22018

perang berupa kepala- kepala lawan yang telah dikalahkan dalam perang sebagai tanda bahwa warga Suku Matabesi telah memenangkan peperangan dalam merebut wilayah kekuasaan terhadap sekitar daerah tersebut serta berterima kasih terhadap leluhur yang telah membantu dalam peperangan (yang memberi kekuatan)

\section{Fatululik}

Fatululik berada tepat diatas aitos yang berfungsi sebagai meja persembahan, untuk meletakan persembahan atau sesajen dalam bentuk sirih pinang bagi para lelehur, dalam suatu upacara adat.

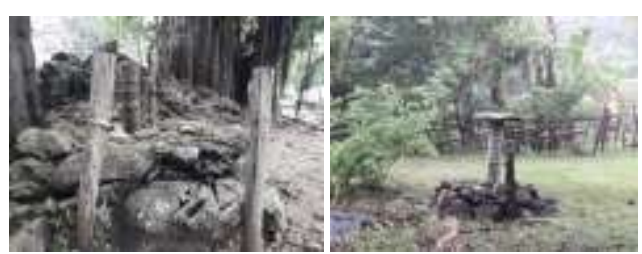

Gambar 4. Tempat Persembahan Dalam Sistem Kepercayaan Masyarakat Suku Matabesi

\section{KESIMPULAN}

Kawasan lanskap budaya Suku Matabesi memiliki 5 significant value yaitu sejarah, ilmu pengetahuan, budaya, agama dan pendidikan.

Potensi yang dimiliki Suku Matabesi dapat dikembangkan menjadi kawasan wisata. Berdasarkan Undang-Undang Kepariwisataan no 10 tahun 2009 tentang daerah tujuan wisata kawasan budaya Suku Matabesi dapat dikembangkan kegiatan wisata yang dapat mendukung ekonomi kreatif masyarakat Suku Matabesi melalui pengembangan fasilitas, pengembangan daya yarik wisata serta pengembangan aksesibilitas yang bersumber dari local wisdom masyarakat Suku Mata Besi.

\section{DAFTAR PUSTAKA}

Nuraini et al. 2015. Significant Value of Senujuh Mountain in Sambas - West Borneo, Conference: IFLA Asia Pasific Congress. Mataram: Indonesia.

Nurisjah S, Pramukonto Q. 2001. Perencanaan Kawasan Untuk Pelestarian Lanskap dan Taman Sejarah.Bogor (ID) Program Studi Arsitektur Pertamanan, Jurusan Budidaya Pertanian (Tidak dipublikasikan) Bogor: Fakultas Pertanian, Institut Pertanian.

Nursyirwan, P.K., Arifin, N.H.S., dan Mugnisjah, W.Q. 2015. Significant of Betawi pekarangan as culturan identity towards development of megacity Jakarta. Proceeding The 5th International Conference of Jabodetabek Study Forum "Sustainable Megacities: Vulnerability, Diversity and Livability", 209-213. Bogor: Crespent Press.

Platcher H., Rossler M. 1995. Cultural Landscape of Universal Value, Gustav Fischer. New York: Verlag.

Supriadi. 2010. Nilai Penting Leang Mandaudeng dan Leang Tengngae. Buletin Somba Opu, 13(17):17-15. 